Revised for Submission to Journal of Applied Microbiology, June 16, 2003.

\title{
Indigenous and contaminant microbes in ultradeep mines
}

T.C. Onstott ${ }^{1}$, D.P. Moser ${ }^{2}$, S.M. Pfiffner ${ }^{3}$, J.K. Fredrickson ${ }^{2}$, F.J. Brockman ${ }^{2}$, T.J. Phelps $^{4}$, D.C. White ${ }^{3}$, A. Peacock ${ }^{3}$, D. Balkwill ${ }^{5}$, R. B. Hoover ${ }^{6}$, L.R. Krumholz 7 , M. Borscik $^{1}$, T.L. Kieft ${ }^{8}$ and R. Wilson ${ }^{9}$

${ }^{1}$ Department of Geosciences, Princeton University, Princeton, NJ 08544

${ }^{2}$ Pacific Northwest National Laboratory, 902 Battelle Blvd., Mail Stop P7-50, PO Box 999, Richland, WA 99352

${ }^{3}$ Department of Microbiology, The University of Tennessee, Center for Biomarker Analysis, 10515 Research Dr., Ste. 300, Knoxville, TN 37932-2575

${ }^{4}$ Environmental Sciences Division, Oak Ridge National Laboratory, PO Box 2008, Oak Ridge, TN 37831-6036

${ }^{5}$ Department of Biological Science, Florida State University, 312 NRB, B-162, Tallahassee, FL 32306

${ }^{6}$ George Marshall Space Flight Center/NASA/NSSTC, SD-50, Huntsville, AL 35812

${ }^{7}$ Department of Botany and Microbiology, Univ. of Oklahoma, 770 Van Vleet Oval, Norman, OK 73019

${ }^{8}$ Department of Biology, 801 Leroy St., New Mexico Institute of Mining and Technology, Socorro, NM 87801

${ }^{9}$ SRK-Turgis Technology, 299 Pendoring St., North Cliff, 2115 South Africa 
Address all correspondence to: T.C. Onstott, Department of Geosciences, Princeton

University, Princeton, NJ 08544, 609-258-2351, Fax: 609-258-1274,

tullis@princeton.edu

\section{Summary}

Rock, air and service water samples were collected for microbial analyses from 3.2 kilometers depth in a working Au mine in the Witwatersrand basin, South Africa. The $\sim 1$ meter wide mined zone was comprised of a carbonaceous, quartz, sulfide, uraninite and Au bearing layer, called the Carbon Leader, sandwiched by quartzite and conglomerates. The microbial community in the service water was dominated by mesophilic aerobic and anaerobic, $\alpha, \beta$ and $\gamma$-Proteobacteria with a total biomass concentration $\sim 10^{4}$ cells $\mathrm{ml}^{-1}$, whereas, that of the mine air was dominated by members of the Chlorobi and Bacteroidetes groups and a fungal component. The microorganisms in the Carbon Leader were predominantly mesophilic, aerobic heterotrophic, nitrate reducing and methylotrophic, $\beta$ and $\gamma$-Proteobacteria that were more closely related to service water microorganisms rather than air microbes. Rhodamine WT dye and fluorescent microspheres employed as contaminant tracers, however, indicated that service water contamination of most of the rock samples was $<0.01 \%$ during acquisition. The microbial contaminants most likely originated from the service water, infiltrated the low permeability rock through and accumulated within mining-induced fractures where they survived for several days prior to being mined. Combined PLFA and terminal restriction 
fragment length profile ( $T$-RFLP) analyses suggest that the maximum concentration of indigenous microorganisms in the Carbon Leader was $<10^{2}$ cells $\mathrm{g}^{-1}$. PLFA, ${ }^{35} \mathrm{~S}$ autoradiography and enrichments suggest that the adjacent quartzite was less contaminated and contained $\sim 10^{3}$ cells/gram of a thermophilic, sulfate reducing bacteria, SRB, some of who are $\delta$ Proteobacteria. Pore water and rock geochemical analyses suggest that these SRB's may have been sustained by sulfate diffusing from the adjacent U-rich, Carbon Leader where it was formed by radiolysis of sulfide.

Key Words: Deep Subsurface; 16S rDNA; PLFA; Microbiology; Carbon Leader; Au mine

\section{Introduction}

The nature of the microbial biomass distribution and microbial community structure in the deep subsurface and the factors that control it, remain largely unknown (Onstott et al., 1998a). Since water at great depths is confined to fractures, microorganisms are expected to be concentrated along the fracture surfaces and to diminish in abundance with increasing distance from the fracture towards the interior matrix of the rock strata. Presumably, geochemical heterogeneity also influences the biomass distribution as it does in relatively shallow environments with much of the biomass localized along interfaces where the electron donor and acceptor flux is higher than within homogenous layers (Krumholz et al., 1997). The porosity and permeability also influence this flux and the movement of microorganisms (Fredrickson et al., 1997). Only a few cores from depths $>1$ kilometer below land surface (kmbls.) have been 